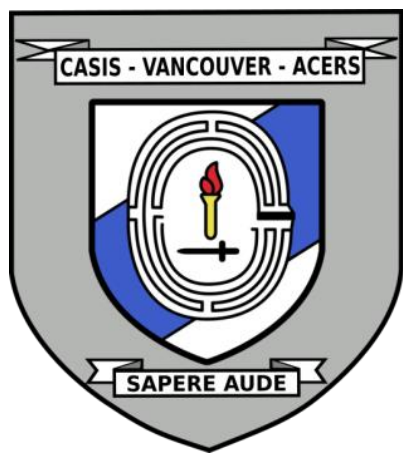

\title{
IDENTITY EXCLUSIVE VIOLENT TRANSNATIONAL SOCIAL MOVEMENTS AND 5TH GENERATION CIVIC WARFARE
}

Date: November 24, 2021

Disclaimer: This briefing note contains the encapsulation of views presented by the speaker and does not exclusively represent the views of the Canadian Association for Security and Intelligence Studies.

\section{KEY EVENTS}

On November 24, 2021, Professor Candyce Kelshall presented on the topic of Identity Exclusive Violent Transnational Social Movements and 5th Generation Civic Warfare at the 2021 CASIS West Coast Security Conference. Primary discussion topics included defining 5th generation warfare, the combatants in 5th generation warfare, Violent Transnational Social Movements (VTSMs), Soft Violence, and how it all fits into contemporary conflict. This presentation was followed by a question and answer period where conference attendees and CASIS Vancouver Executives were provided with an opportunity to engage in discussion with Professor Kelshall and other speakers.

\section{NATURE OF DISCUSSION}

\section{Presentation}

The main theme of the presentation was 5th generation warfare and its possible combatants. An overview of the distinction between warfare and war was provided, as well as the importance of differentiating social movements from VTSMs and terrorist groups. Professor Kelshall also examined the contemporary character of war.

\section{Question Period/Breakout Room Discussion}

During the question and answer period, the key differentiating factors between social movements, VTSMs, and terrorist groups were further discussed. Professor Kelshall also touched upon the concept of fifth generation warfare when examining contemporary conflict and the importance of encouraging 
younger generations to engage in dialogue with those who have different perspectives.

\section{BACKGROUND}

\section{Presentation}

Professor Kelshall began her presentation by examining the type of conflict visible today. To this, she explained that we are, arguably, seeing hybrid actors crossing all spectrums. She proceeded to note the wide variety of intersectionality seen between groups including territorially demarked gangs, who act as militias engaging in organized crime group behaviour for profit while seeking political influence; extremists who are called domestic terrorists; and even terrorists who are referred to as having mental illness. Professor Kelshall explained that these issues are being dealt with through single jurisdiction conventional beat policing and thematic policing in which separate units are dealing with separate issues rather than acknowledging that today's hybrid actors have become transnational, creating a community, culture, and identity.

Given the variety in conflict visible today, it could be possible to tell whether there is a new form of warfare emerging by potentially understanding the nature, character, and iterations of warfare, which might help to understand the current environment. To explain this, Professor Kelshall first went into defining both warfare and war as concepts. Warfare can best be understood in the context of conflict, whereby political conflict can be an expression of differences in views and perspectives by the people or groups who make up the state. Furthermore, conflict is intragroup based, and it might be considered population centric. War, on the other hand, was described as the time when states are at odds or have differences with each other, leading them to a war. War might, therefore, be seen as state centric, not population centric. Professor Kelshall argued that the first four generations of warfare have been state-centric, adding that the fifth generation of warfare might be seen as a war that has changed in nature, and the objective of the conflict is no longer state-centric but population centric and identity-based.

The actors who wage non-state centric war might be considered VTSMs, which are polycentric, reticulate, and segmentary in nature - meaning they do not have a centralised leadership or command structure; they are networked and can express many different issues simultaneously, making the movement seem disorganized or disjointed while also making them adaptable and resilient. While all social movements are polycentric, reticulate, and segmentary, VTSMs are 
primarily extremist in nature, violent in expression, and identity exclusive. They transcend state boundaries to unite individuals who are predisposed to violence, which may be soft or kinetic, and share ideologies, perspectives, or grievances particular to an identity.

VTSMs arise from echo chambers, strengthening and solidifying existing beliefs shifting the meta-opinion of identity-based groups, often increasing polarisation and instances of "othering". An echo chamber could be seen as the virtual or physical space where group members exclusively share and engage with similar content that is already believed by the individual members. Professor Kelshall noted that in a study conducted by Clark McCauley and Sophia Moskalenko in 2016, they found that the meta-narrative in echo chambers shifts progressively toward the extreme as members generate increasingly absolute content. As this meta-narrative shifts, individuals within these echo chambers are increasingly likely to become radicalised or to become violent extremists. Soft violence is the main communication, recruitment, and radicalisation tool of VTSMs, as well as the main weapon used to further identity-based violence. These actions entrench or highlight superiority of one group over another without necessarily having a physical or kinetic impact.

Professor Kelshall further noted that the difference between social movements and VTSMs is that social movements are inclusive, cause and issue based, and use activism to cause change in disparity. VTSMs, on the other hand, are identity exclusive and based in identity welfare, seeking the preservation and maintenance of dominance, legitimacy, authority, and superiority of an identity; violence is their primary tool used. Furthermore, she differentiated terrorists from violent extremists by highlighting that terrorists act on a specific issue, which is political in intent. They use violence to further an objective; amplify their cause by kinetic acts, not by weight of association with others; justify kinetic acts with an ideology; and are clandestine in nature. Violent extremists often have multiple causes which are not specific issues related to identity welfare; use social movements to amplify causes; and use weight of association to justify the movement. The aim of violent extremists is to spread soft violence-actions that fall short of criminally identifiable physical violence but that it is still considered violence - as widely and publicly as possible. It is worth noting that violence does not necessarily have to be kinetic to be considered violence.

Professor Kelshall continued by going into the nature of war stating that the purpose and role of fighting is focused, legally and in practice, on state-based dominance and state-based warfare against enemies of the state and its sovereignty. Defeat can be observed through disintegration, implosion, 
confusion, and civil war. However, the character of war is constantly and consistently changing at a radical pace to match technological advances, with even disinformation being used as a weapon of war.

Professor Kelshall concluded her presentation by summarising fifth generation warfare as groups against groups, not against the state necessarily, which are enabled by shifts of political and social loyalties to identity. One could argue that the power of smaller entities is increasing in a loose informal network or networked nodes that distribute information on how, what, and who to fight. As the nodes operate independently, grooming is no longer necessary since there is no need for physical contact or connectivity. Professor Kelshall used Moghaddam's staircase to violence to show that the traditional understandings of radicalisation suggest that as an individual moves up the staircase of traditional radicalisation, there are fewer alternatives to an individual acting in a kinetically violent manner. However, by going down the staircase, it demonstrates how people with poor metacognition might begin the journey to becoming violent extremist actors and how supporters and sympathizers contribute to the compression of extremist sentiments.

\section{Question Period/Breakout Room Discussion}

In this section Professor Kelshall furthered the conversation on the importance of differentiating extremists, VTSMs, and terrorists as she discussed how the analysis behind the organisational structure demonstrates each group has its own distinguishable characteristics, including how soft or kinetic violence could be used as the primary tool. However, she also noted that there are times when some groups might, for example, look like a militia or a gang when, in fact, they have become a VTSM. Therefore, it is important to be aware and understand the concept of identity as the driver for each group.

Professor Kelshall also noted that despite fifth generation warfare possibly being a return to pre-Westphalian order, it is important to understand that modern contemporary conflict has become hybrid, transnational, and ever-changing due to technological advances.

Professor Kelshall also stated that dialogue and critical thinking are the most effective methods to get through the VTSMs space. Professor Kelshall stated that telling younger generations not to engage with trolls to avoid being attacked is problematic for the future national security workforce. This kind of reasoning amounts to training them not to learn to dialogue or communicate with people who have different perspectives than them. Subtly and unintentionally, they are 
being taught to accept something so they can tolerate it in the societies that they live in.

\section{KEY POINTS OF DISCUSSION}

\section{Presentation}

- Fifth generation warfare might be seen as a war that has changed in nature and the objective of the conflict is no longer state-centric but population centric and identity based.

- The actors who wage non-state centric war might be considered a part of violent transnational social movements (VTSMs), which are polycentric, reticulate, and segmentary in nature.

- VTSMs arise from echo chambers, strengthening and solidifying existing beliefs shifting the meta-opinion of identity-based groups, often increasing polarisation and instances of "othering".

- Fifth generation warfare can, arguably, be seen as groups against groups, not against the state necessarily, which are enabled by shifts of political and social loyalties to identity.

- Extremists are so much more than single cause political actors like terrorists, and it is possible that our conflation of the two could spell danger to democracy and social harmony.

\section{Question Period/Breakout Room Discussion}

- VTSMs, violent extremists, and terrorists each have their own distinguishable characteristics when examining them through their organizational structures.

- Despite fifth generation warfare possibly being a return to pre-Westphalian order, contemporary conflict has become hybrid, transnational in nature, and ever-changing.

- Dialogue and critical thinking are the most effective methods to get through the VTSMs space. 


\section{(c) (1) $(9)$}

Commercial-NoDerivatives 4.0 International License.

(C) (CANDYCE KELSHALL, 2022)

Published by the Journal of Intelligence, Conflict, and Warfare and Simon Fraser University

Available from: https://jicw.org/ 